\title{
SELECTIVE ETCHING OF WIDE BANDGAP NITRIDES

${ }^{a}$ R. J. Shul, ${ }^{a}$ C. G. Willison, a M. M. Bridges, a J. Han, ${ }^{b}$ J. W. Lee, ${ }^{b}$ S. J. Pearton, ${ }^{b}$ C. R. Abernathy, ${ }^{\mathrm{b}} \mathrm{J}$. D. MacKenzie, and ${ }^{\mathrm{b}} \mathrm{S}$. M. Donovan CONF- $971201-$

aSandia National Laboratories, Albuquerque, NM 87185-0603, rjshul@sandia.gov

bUniversity of Florida, Department of Materials Science and Engineering, Gainesville, FL 32611

\begin{abstract}
High-density plasma etching has been an effective patterning technique for the group-III nitrides due to ion fluxes which are 2 to 4 orders of magnitude higher than more conventional reactive ion etch (RIE) systems. GaN etch rates exceeding $0.68 \mu \mathrm{m} / \mathrm{min}$ have been reported in $\mathrm{Cl}_{2} / \mathrm{H}_{2} / \mathrm{Ar}$ inductively coupled plasmas (ICP) at $-280 \mathrm{~V} \mathrm{dc}$-bias. Under these conditions, the etch mechanism is dominated by ion bombardment energies which can induce damage and minimize etch selectivity. High selectivity etch processes are often necessary for heterostructure devices which are becoming more prominent as growth techniques improve. In this study, we will report high-density ICP etch rates and selectivities for GaN, AIN, and InN as a function of cathode power, ICP-source power, and chamber pressure. GaN:AlN selectivities > 8:1 were observed in a $\mathrm{Cl}_{2} / \mathrm{Ar}$ plasma at $10 \mathrm{mT}$ Trr pressure, $500 \mathrm{~W}$ ICP-source power, and $130 \mathrm{~W}$ cathode rf-power, while the GaN:InN selectivity was optimized at $\sim 6.5: 1$ at $5 \mathrm{mTorr}, 500 \mathrm{~W}$ ICP-source power, and $130 \mathrm{~W}$ cathode rf-power.
\end{abstract}

\section{INTRODUCTION}

The majority of plasma etch development for group-III nitride materials has been directed toward photonic devices where high-rate, anisotropic, equi-rate etching is required. Recently, interest in high power, high temperature electronic devices has increased which has changed many of the etch requirements due to shallower etch depths than those required for photonic devices. The etch requirements for these devices often include smooth surface morphology, low damage, and selective etching of one material over another. This is especially critical for high electron mobility transistors (HEMTs) to control threshold voltage uniformity, heterojunction bipolar transistors (HBTs) to accurately stop on either the emitter or collector regions for metal contacts, and for low resistivity n-ohmic contacts on InN layers.

High-density plasma etch systems have shown excellent patterning results for group-III nitrides. ${ }^{1-10}$ The high plasma flux generated in these systems enhances the bond breaking efficiency of the nitrides and the sputter desorption of the etch products. Unfortunately, the best etch results for these materials are often obtained at relatively high dc-bias, $>-200 \mathrm{~V}$, which can minimize etch selectivity and induce plasma damage. However, variations in plasma conditions can often change etch selectivity of one material over another by optimizing the chemical:physical ratio of the etch mechanism. We have recently reported ICP etch rates and selectivities for GaN, AlN, and InN in a variety of $\mathrm{Cl}_{2}$ - and $\mathrm{BCl}_{3}$-based plasma chemistries. ${ }^{11}$ Selectivities for GaN:AlN of 5.6:1 and for $\mathrm{GaN}: \mathrm{InN}$ of $\sim 2.7: 1$ were obtained in a $\mathrm{Cl}_{2} / \mathrm{Ar}(25 / 5)$ plasma. In this study, we will observe the effect of pressure, source power, and cathode rf-power on the etch selectivity.

\section{EXPERIMENT}

The GaN films etched in this study were grown by metal organic chemical vapor deposition (MOCVD), whereas the AIN and InN samples were grown using metal organic-molecular beam epitaxy (MO-MBE). The ICP reactor was a load-locked Plasma-Therm SLR 770 which used a 2 $\mathrm{MHz}, 3$ turn coil ICP source. All samples were mounted using a thermally conductive paste on an anodized $\mathrm{Al}$ carrier that was clamped to the cathode and cooled with He gas. The ion energy or dcbias was defined by superimposing an rf-bias $(13.56 \mathrm{MHz})$ on the sample. Samples were patterned with Shipley 4330 photoresist. Etch rates were calculated from the depth of etched

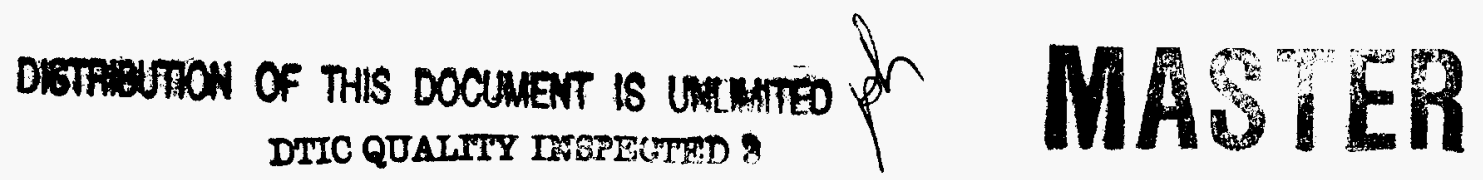




\section{DISCLAIMER}

This report was prepared as an account of work sponsored by an agency of the United States Government. Neither the United States Government nor any agency thereof, nor any of their employees, makes any warranty, express or implied, or assumes any legal liability or responsibility for the accuracy, completeness, or usefulness of any information, apparatus, product, or process disclosed, or represents that its use would not infringe privately owned rights. Reference herein to any specific commercial product, process, or service by trade name, trademark, manufacturer, or otherwise does not necessarily constitute or imply its endorsement, recommendation, or favoring by the United States Government or any agency thereof. The views and opinions of authors expressed herein do not necessarily state or reflect those of the United States Government or any agency thereof. 
features measured with a Dektak stylus profilometer after the photoresist was removed. Depth measurements were taken at a minimum of 3 positions. Samples were $\sim 1 \mathrm{~cm}^{2}$ and were exposed to the plasma for 1 to 3 minutes.

\section{RESULTS AND DISCUSSIONS}

$\mathrm{GaN}, \mathrm{AlN}$, and $\mathrm{InN}$ etch rates are shown in Figure 1 as a function of $\% \mathrm{Ar}$ in a $\mathrm{Cl}_{2} / \mathrm{Ar}$ plasma at $500 \mathrm{~W}$ ICP source power, $2 \mathrm{mT}$ Trr chamber pressure, and $130 \mathrm{~W}$ cathode rf-power. As the $\% \mathrm{Ar}$ concentration increased, GaN and $\mathrm{AlN}$ etch rates initially increased and then decreased at $>20 \%$ Ar. The initial increase in etch rate was attributed to more efficient sputter desorption of the etch products by the Ar ions. However, at higher \%Ar, the etch rates decreased due to a lower concentration of $\mathrm{Cl}$ radicals in the plasma. InN etch rates generally increased as the \%Ar increased implying that physical sputtering was a major contributor to the etch mechanism. The strong physical dependence of the InN etch mechanism may be a consequence of low volatility $\mathrm{InCl}_{3}$ etch products formed at $25^{\circ} \mathrm{C}$ which must be sputter desorbed from the surface to prevent passivation. Gas ratios were held constant throughout the rest of this study at $5: 1 \mathrm{Cl}_{2}$ :Ar with a total flow of 30 sccm.

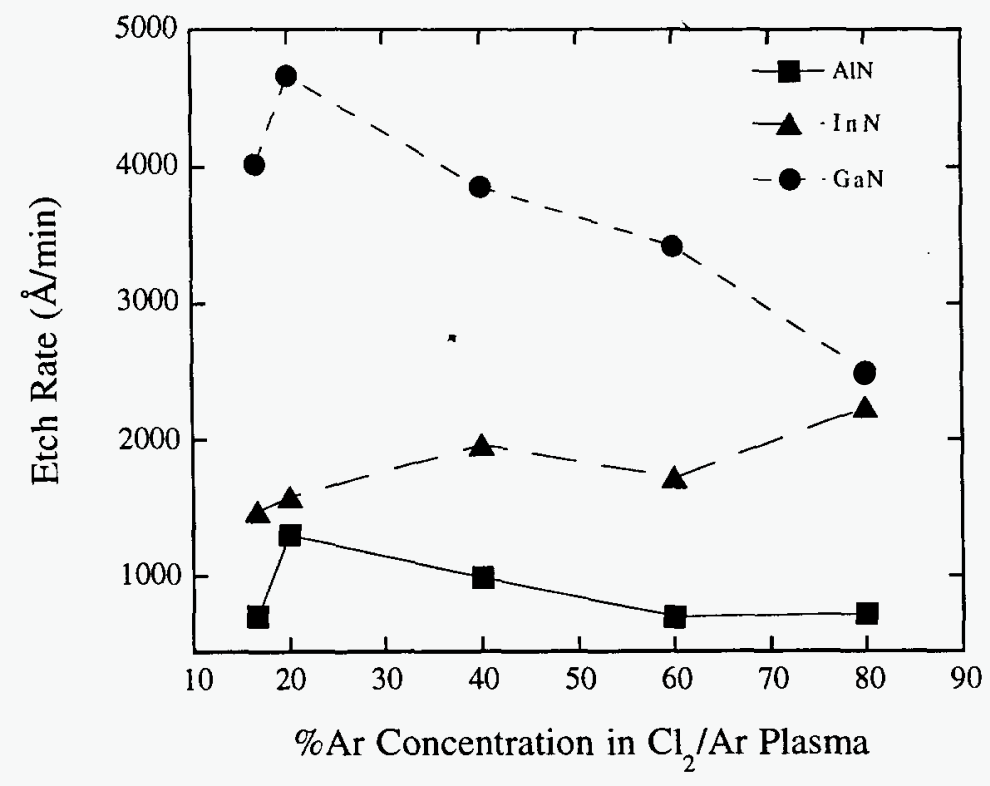

Figure 1. GaN, InN, and AlN etch rates as a function of $\% \mathrm{Ar}$ in a $\mathrm{Cl}_{2} / \mathrm{Ar} \mathrm{ICP}$ plasma. Plasma conditions were: 2 mTorr pressure, ICP-source power $500 \mathrm{~W},-250 \pm 50 \mathrm{~V}$ dc-bias, and $25^{\circ} \mathrm{C}$ cathode temperature.

Plasma conditions change quite dramatically as a function of pressure, in particular the mean free path decreases and the collisional frequency increases as the pressure is increased. This results in changes in both ion energy and plasma density which strongly influence the etch properties. In Figure 2, as the pressure was increased to $5 \mathrm{mTorr}$, the GaN etch rate increased slightly indicating a reactant limited regime. However, as the pressure was increased further, the GaN etch rates decreased due to either higher ion energies, lower plasma densities, redeposition, or polymer formation on the substrate surface. In general, InN and AlN etch rates decreased with increasing pressure. As shown in Figure 3, the GaN:AlN etch selectivity reached a maximum of $\sim 8.5: 1$ at $10 \mathrm{mTorr}$ while the $\mathrm{GaN}$ :InN selectivity $6.8: 1$ at $5 \mathrm{mT}$ Torr. At $20 \mathrm{mTorr}$ selectivites were $<1: 1$. 


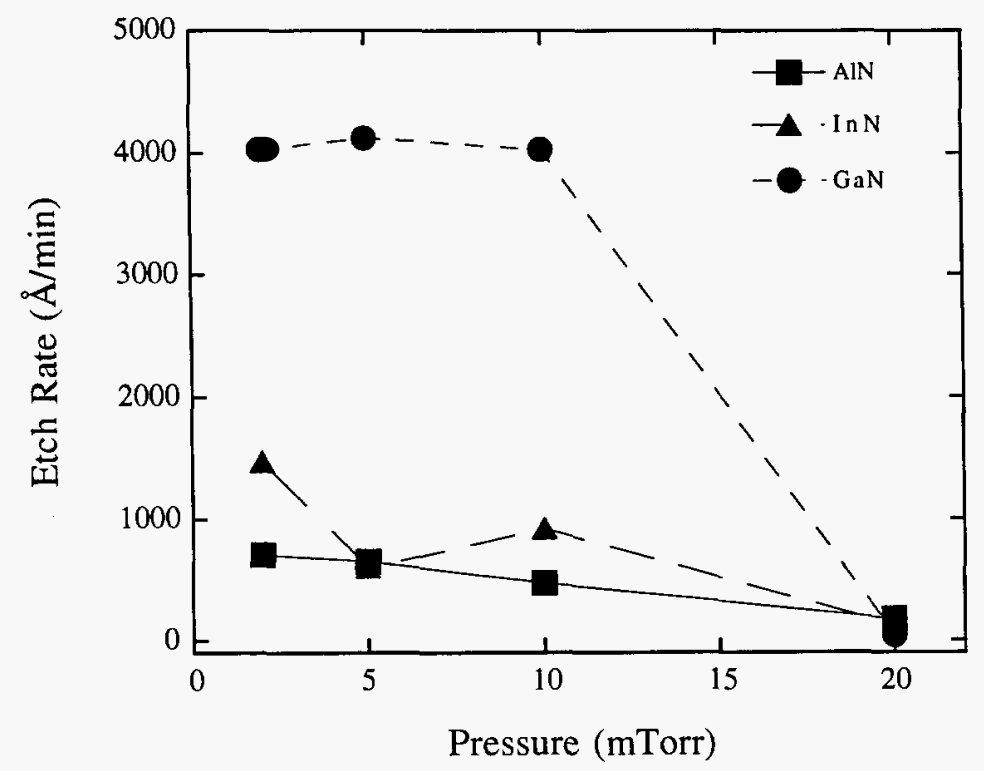

Figure 2. GaN, InN, and AlN etch rates as a function of chamber pressure. Plasma conditions were: $25 \mathrm{sccm} \mathrm{Cl}{ }_{2}, 5 \mathrm{sccm} \mathrm{Ar}, 500 \mathrm{~W}$ ICP-source power, $130 \mathrm{~W}$ rf-cathode power, and $25^{\circ} \mathrm{C}$ cathode temperature.

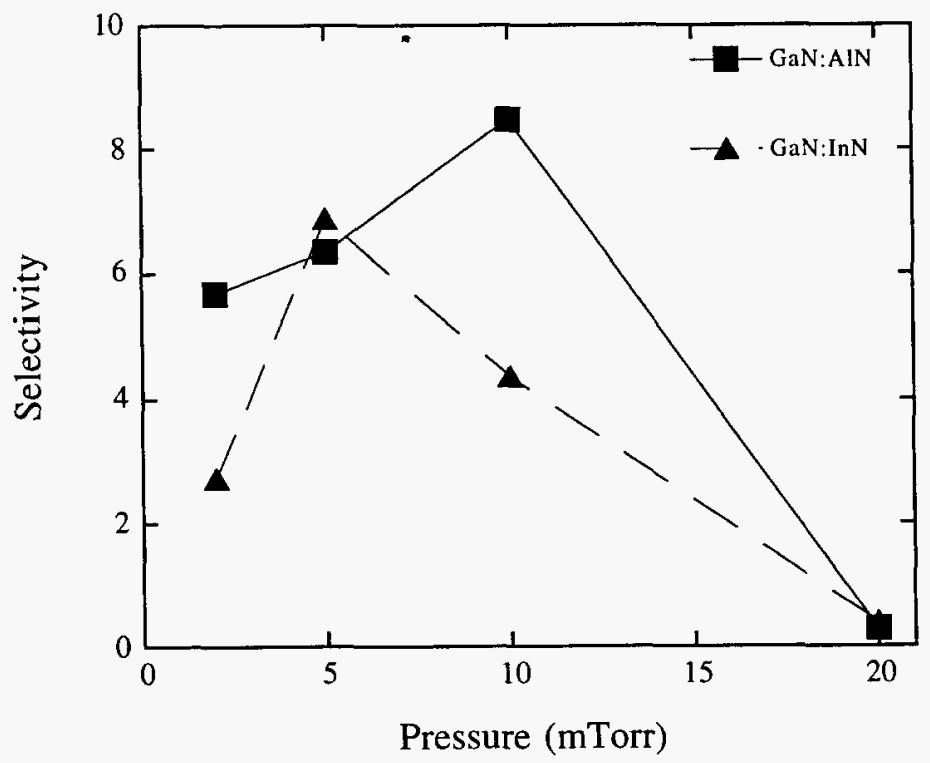

Figure 3. GaN:AIN and GaN:InN etch selectivities as a function of chamber pressure. Plasma conditions were: $25 \mathrm{sccm} \mathrm{Cl}, 5 \mathrm{sccm} \mathrm{Ar}, 500 \mathrm{~W}$ ICP-source power, $130 \mathrm{~W}$ rf-cathode power, and $25^{\circ} \mathrm{C}$ cathode temperature.

As a function of increasing plasma density or source power, etch rates typically increase due to higher concentrations of reactive neutrals which increases the chemical component of the etch mechanism and/or higher ion flux which increases both the bond breaking efficiency of the nitrides and the sputter desorption of etch products after they have formed. The effects of ion energies and plasma densities are more obvious for high-density plasma systems since they can be more 
effectively decoupled as compared to RIE. In Figure 4, GaN, InN, and AlN etch rates are shown as a function of ICP-source power. At 0 ICP-source power, the etch rates were very slow. Under these conditions, the etch system essentially operated as a RIE where the plasma density was typically 2 to 4 orders of magnitude less than those formed in ICP. As soon as the ICP-source power was turned on significant etching occurred. The etch rates for all 3 films initially increased with ICP source power due to higher neutral and ion flux. The InN etch rates decreased at $>250$ $\mathrm{W}, \mathrm{GaN}$ decreased $>500 \mathrm{~W}$, and AlN increased over the range of powers studied. The observed decrease in etch rates at high source power was due to either saturation of reactive neutrals at the sample surface or sputter desorption of the $\mathrm{Cl}$ radicals before they have time to react with the surface. In Figure 5, The GaN:AlN etch selectivity follows the same trend as the GaN etch rate with an initial increase followed by a decrease at $750 \mathrm{~W}$, whereas the GaN:InN increased with ICP power.

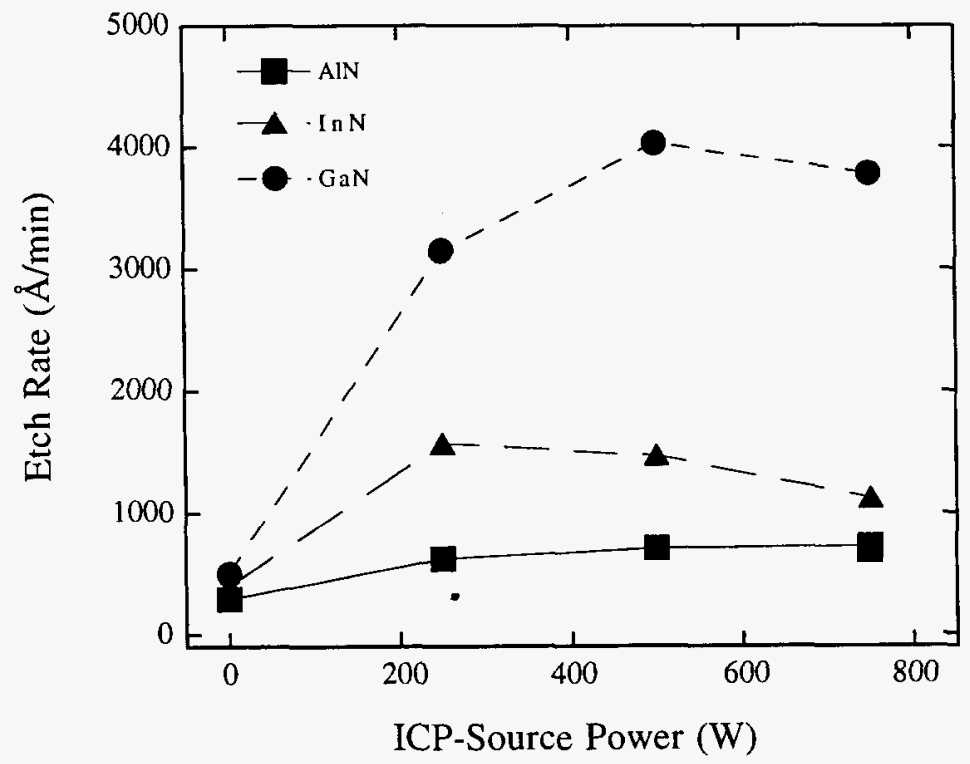

Figure 4. GaN, InN, and AIN etch rates as a function of ICP-source power. Plasma conditions were: $25 \mathrm{sccm} \mathrm{Cl}, 5 \mathrm{sccm} \mathrm{Ar}, 2$ mTorr chamber pressure, $130 \mathrm{~W}$ rf-cathode power, and $25^{\circ} \mathrm{C}$ cathode temperature.

Ion energies can influence the physical component of the etch mechanism by changing the sputter desorption and bond breaking efficiencies of the etch process. In Figure 6, etch rates for all 3 films increased with increasing cathode rf-power which corresponds closely to ion energy. Faster rates were attributed to highly efficient breaking of the nitride bonds and sputter desorption of the etch products at higher ion energies. Increasing InN etch rates were especially significant since $\mathrm{InCl}_{3}$ was the prominent etch product under these conditions. $\mathrm{InCl}_{3}$ has a low volatility and typically requires high etch temperatures to increase the volatility and yield reasonable etch rates. Under high dc-bias conditions, the fast $\mathrm{InN}$ etch rates were attributed to efficient sputter desorption of the $\mathrm{InCl}_{3}$ etch products prior to passivation of the etch surface. ${ }^{12}$ The etch selectivities tracked identically as a function of rf-power (see Figure 7), decreasing as the physical component of the etch mechanism became more prominent. 


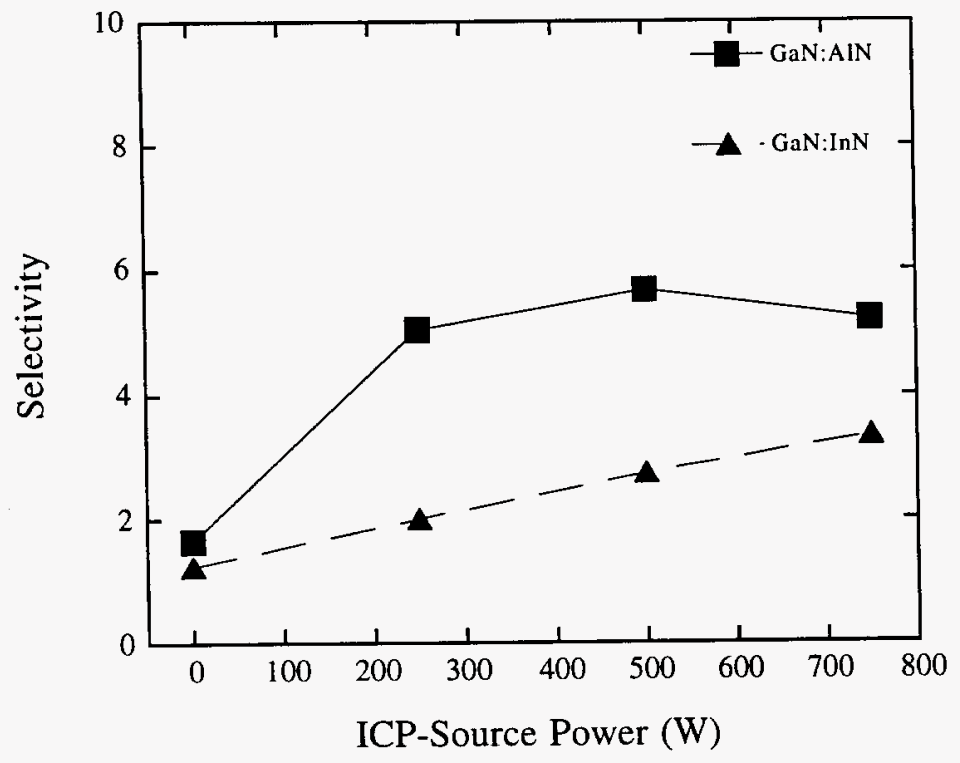

Figure 5. GaN:AlN and GaN:InN etch selectivities as a function of ICP source-power. Plasma conditions were: $25 \mathrm{sccm} \mathrm{Cl} \mathrm{cl}_{2}, 5 \mathrm{sccm} \mathrm{Ar}, 2 \mathrm{mTorr}$ chamber pressure, $130 \mathrm{~W}$ rf-cathode power, and $25^{\circ} \mathrm{C}$ cathode temperature.

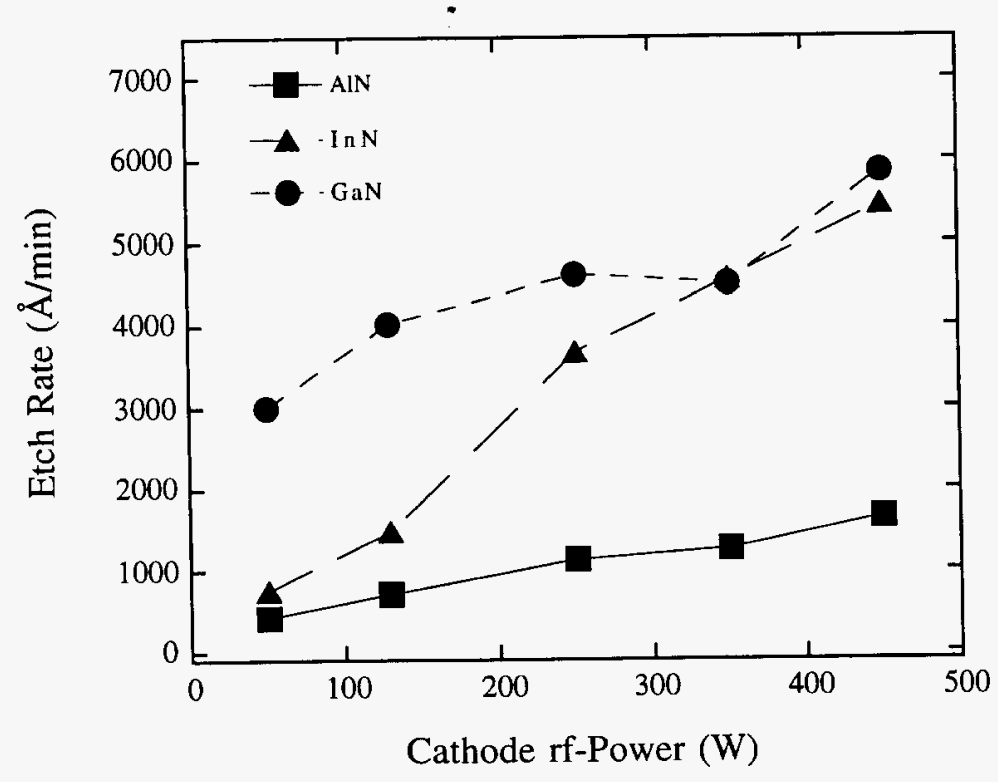

Figure 6. GaN, InN, and AlN etch rates as a function of cathode rf-power. Plasma conditions were: $25 \mathrm{sccm} \mathrm{Cl}{ }_{2}, 5 \mathrm{sccm} \mathrm{Ar}, 2$ mTorr chamber pressure, $500 \mathrm{~W}$ ICP-source power, and $25^{\circ} \mathrm{C}$ cathode temperature. 


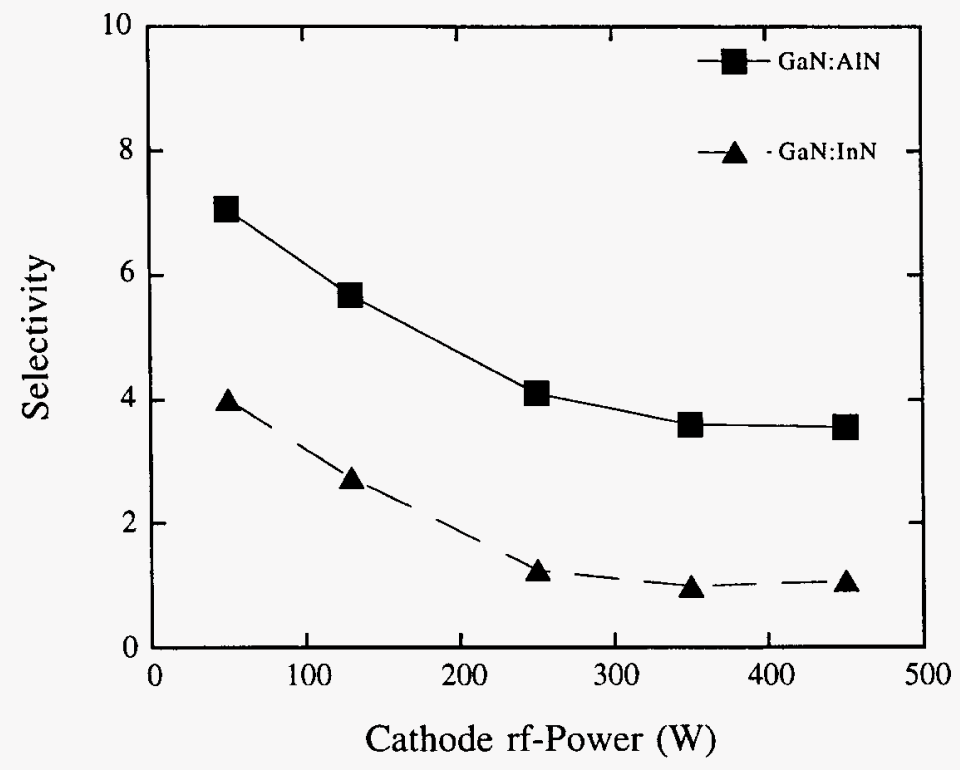

Figure 7. GaN:AlN and GaN:InN etch selectivities as a function of cathode rf-power. Plasma conditions were: $25 \mathrm{sccm} \mathrm{Cl} 2,5 \mathrm{sccm} \mathrm{Ar,} 2$ mTorr chamber pressure, $500 \mathrm{~W}$ ICP-source power, and $25^{\circ} \mathrm{C}$ cathode temperature.

\section{CONCLUSIONS}

In summary, chamber pressure, source power, and cathode rf-power have significant effects on etch selectivity. Due to their strong bond energies, etching the group-III nitrides requires either high ion energies or high ion flux at energies above the bond-breaking threshold energy. Very significant etching of InN was obtained under high ion energy conditions implying effective sputter desorption of the low-volatility $\mathrm{InCl}_{3}$ etch products. The highest GaN:AlN selectivity was obtained at 10 mTorr while the highest selectivity for GaN:InN was obtained at $5 \mathrm{mTorr}$. In general, selectivities improved as the ion flux increased but decreased as ion energy increased. Etch selectivity for the group-III nitrides is highly dependent on ion/neutral flux and ion energy.

\section{ACKNOWLEDGMENTS}

Sandia is a multiprogram laboratory operated by Sandia Corporation, a Lockheed Martin Company, for the United States Department of Energy under contract DE-ACO4-94AL85000. 


\section{REFERENCES}

1. M. E. Lin, Z. F. Fan, Z. Ma, L. H. Allen, and H. Morkoc, Appl. Phys. Lett. 64, 887 (1994)

2. R. J. Shul, S. P Kilcoyne, M. Hagerott Crawford, J. E. Parmeter, C. B. Vartuli, C. R. Abernathy, and S. J. Pearton, Appl. Phys. Lett. 66, 1761 (1995).

3. L. Zhang, J. Ramer, J. Brown, K. Zheng, L. F. Lester, and S. D. Hersee, Appl. Phys. Lett. 68, 367 (1996).

4. S. J. Pearton, C. R. Abernathy, and F. Ren, Appl. Phys. Lett. 64, 2294 (1994).

5. H. Lee, D. B. Oberman, and J. S. Harris, Jr., Appl. Phys. Lett. 67, 1754 (1995).

6. C. B. Vartuli, S. J. Pearton, J. W. Lee, J. Hong, J. D. MacKenzie, C. R. Abernathy, and R. J. Shul, Appl. Phys. Lett. 69, 1426 (1996).

7. C. B. Vartuli, J. D. MacKenzie, J. W. Lee, C. R. Abernathy, S. J. Pearton, and R. J. Shul, J. Appl. Phys. 80, 3705 (1996).

8. R. J. Shul, in GaN and Related Materials, ed. S. J. Pearton (Gordon and Breach, NY 1997).

9. R. J. Shul, G. B. McClellan, S. A. Casalnuovo, D. J. Rieger, S. J. Pearton, C. Constantine, C. Barratt, R. F. Karlicek, Jr., C. Tran, and M. Schurman, Appl. Phys. Lett. 69, 1119 (1996).

10. R. J. Shul, R. D. Briggs, J. Han, S. J. Pearton, J. W. Lee, C. B. Vartuli, K. P. Killeen, and M. J. Ludowise, Mat. Res. Soc. Symp. Proc. 468, 355 (1997).

11. R. J. Shul, C. G. Willison, M. M. Bridges, J. Han, J. W. Lee, S. J. Pearton, C. R. Abernathy, J. D. MacKenzie, S. M. Donovan, L. Zhang, and L. F. Lester, J. Vac. Sci. Technol. A, submitted (1997).

12. J. W. Lee, J. Hong, and S. J. Pearton, Appl. Phys. Lett. 68, 847 (1996). 
M98002674
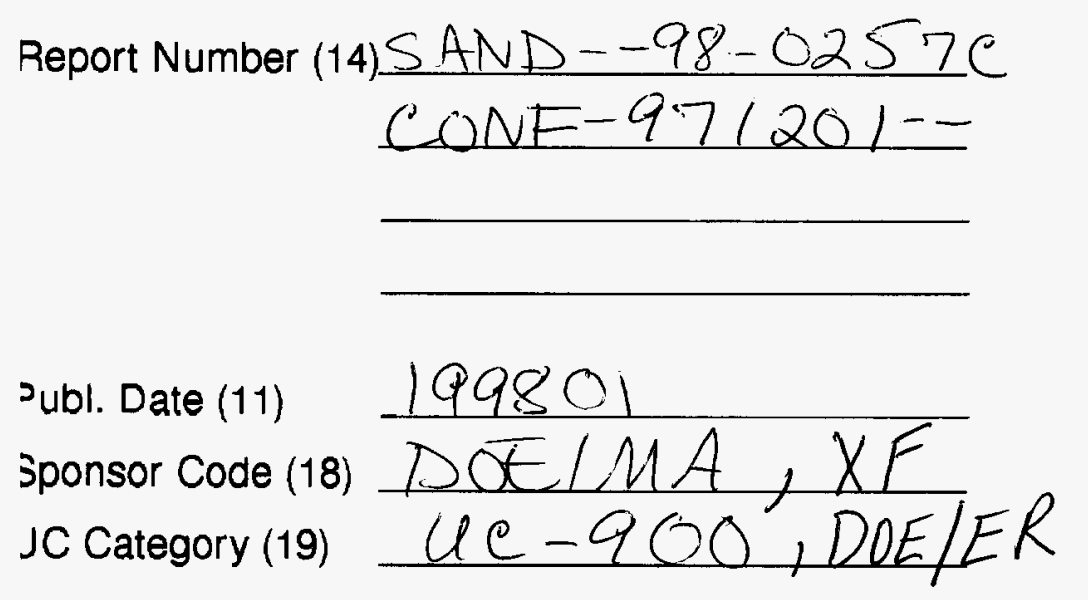

DOE 